\title{
Phenytoin induced drug rash with eosinophilia and systemic symptoms syndrome: a case report
}

\author{
Yogesh Devaraj ${ }^{1}$, Sathyanarayana Dasegowda Belagola ${ }^{1}$, Ranga Swaroop Mukunda ${ }^{1}$, \\ Ravi Shankar Manchukonda ${ }^{2} *$, Puneetha Basavanaik ${ }^{1}$, Aneesa K. Hasanabba ${ }^{1}$, \\ Priyanka Kumari ${ }^{1}$
}

\begin{abstract}
${ }^{1}$ Department of Dermatology, Adichunchanagiri Institute of Medical Sciences, B.G. Nagar, India

${ }^{2}$ Department of Pharmacology, Adichunchanagiri Institute of Medical Sciences, B.G. Nagar, India
\end{abstract}

Received: 04 March 2016

Accepted: 04 April 2016

\section{*Correspondence to:}

Dr. Ravi Shankar Manchukonda, Email: ravipharmac

@yahoo.com

Copyright: (C) the author(s), publisher and licensee Medip Academy. This is an openaccess article distributed under the terms of the Creative Commons Attribution NonCommercial License, which permits unrestricted noncommercial use, distribution, and reproduction in any medium, provided the original work is properly cited.

\begin{abstract}
DRESS syndrome (drug rash with eosinophilia and systemic symptoms) is a severe adverse drug reaction characterised by rash, fever, lymphadenopathy and internal organ involvement. Although the death rate can reach $10 \%$, rapid diagnosis and prompt withdrawal of the offending drug is the key to limit morbidity and mortality. The potential role of corticosteroids remains controversial. We report a case of a 45 -year-old male patient who suffered a head injury, for which he was prescribed phenytoin. Five weeks later he developed features of DRESS syndrome including facial and peri-orbital oedema, generalized erythematous, maculo-papular rash, conjunctivitis, inguinal lymphadenopathy, leucocytosis, eosinophilia and elevated liver enzymes. Skin biopsy revealed acanthosis and spongiosis of epidermis and dense inflammatory cell infiltrate comprising eosinophils and lymphocytes. In this case, causalty assessment using Naranjo adverse drug reaction probability scale showed that phenytoin was a probable cause for the adverse drug reaction (score-7). Phenytoin was immediately stopped and patient was treated with systemic corticosteroids. The patient improved dramatically within the next few days. Early recognition of symptoms of DRESS and immediate withdrawal of the offending drug followed by prompt treatment with corticosteroids and other supportive measures will ensure quick recovery and will avoid fatal outcomes.
\end{abstract}

Keywords: DRESS syndrome, Maculo-papular rash, Eosinophilia, Phenytoin, Systemic corticosteroids, Naranjo ADR probability scale.

\section{INTRODUCTION}

Drug rash with eosinophilia and systemic symptoms syndrome also known as DRESS syndrome is a severe drug-induced hypersensitivity reaction. Although the etiology of DRESS is poorly understood, genetic susceptibility markers have been identified within the HLA complex and there are several prevailing models of pathogenesis. Modification of host antigens by haptens (drugs or their metabolites) or non-covalent drug binding to endogenous proteins may drive pro-inflammatory immune responses in patients. Alternatively, a viral trigger for DRESS has been proposed based on the concomitant detection of herpes viruses and the recent demonstration of Epstein-Barr virus-specific immune responses in DRESS patients. ${ }^{1}$ This syndrome is characterized by fever, generalized maculo-papular rash, facial oedema, exfoliative dermatitis, lymphadenopathy, eosinophilia, leukocytosis, and involvement of internal organs. Fatal cases are reported with an estimated mortality of up to $10 \%$ largely due to multi-organ dysfunction. Diagnosis is challenging because the extent of skin involvement does not always correlate with the extent of internal organ involvement and therefore early recognition of symptoms is vital to minimize morbidity and mortality. Management involves prompt cessation of the culprit drug, administration of corticosteroids and supportive treatment. We report a case of a 45 year old 
man who developed DRESS due to phenytoin and improved dramatically with our treatment.

\section{CASE REPORT}

A 45 year old man presented with history of itching and burning sensation all over the body since 1 week, swelling of both eyelids and discharge from eyes since 3 days and left ear discharge since a day. Itching and burning sensation initially started over hands and face and progressed to the entire body. Patient then developed erythema and maculo papular rash predominantly over face, limbs and trunk. This was followed by facial and peri orbital oedema and oedema of the hands. Patient then developed vesicular lesions over dorsum of hands. Oozing and crusting of the lesions occurred followed by scaling over the face, upper chest and scalp over a period of 2 days. There was also history of pain and swelling in the small joints.

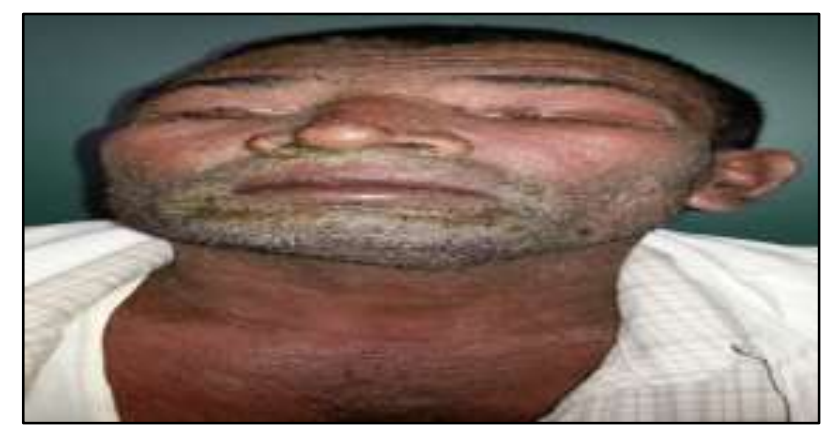

Figure 1: Facial and peri-orbital oedema with papulovesicular lesions.

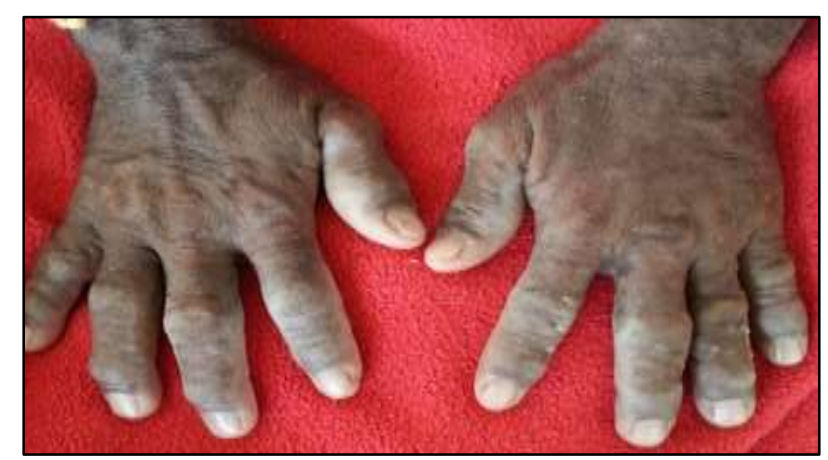

Figure 2: Oedema of the hands with papulo-vesicular lesions.

Patient suffered a head injury 6 weeks back. CT scan of brain showed frontal contusion and left temporal subdural haemorrhage for which he was prescribed tablet phenytoin $300 \mathrm{mg}$ by a neurologist to prevent posttraumatic convulsions. Five weeks later he developed the above symptoms. There was no history of contact with plant allergens and no history of similar episodes in the past.

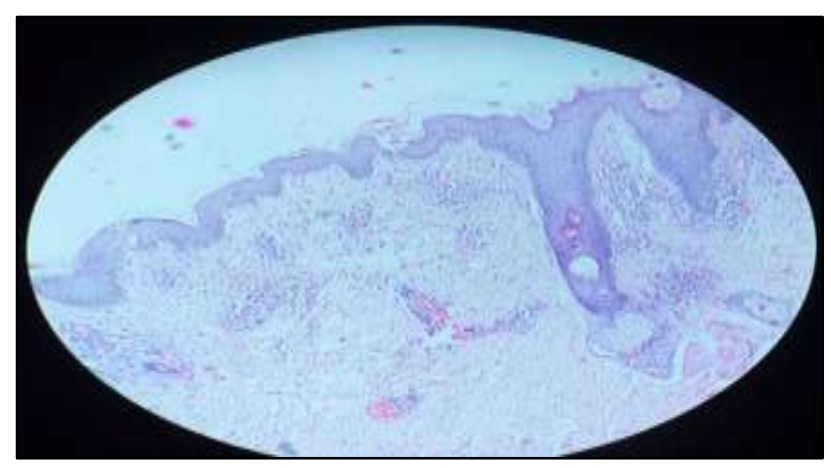

Figure 3: Epidermis showing acanthosis and spongiosis with dense inflammatory cell infiltrate predominantly eosinophils and lymphocytes. (Hematoxylin and eosin stain; magnification: $\times 10$ ).

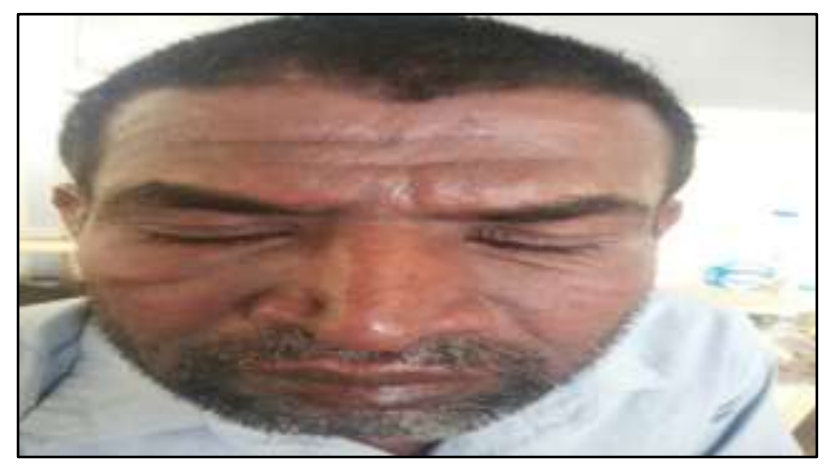

Figure 4: Facial oedema, erythema and oozing of lesions decreased after 2 days of treatment.

On examination patient was febrile and oedematous swelling of face and eyelids (Figure 1) was noted. A generalised, erythematous, maculo papular rash was seen over the neck, chest, abdomen, back, upper limbs and thighs. Multiple papulo vesicular lesions were present over the face, dorsum of hands (Figure 2), palms and soles with oozing and crusting around the mouth and nasolabial folds. Scales were present over the neck, chest, upper limbs and lower limbs. Crusted plaques were seen over the scalp. Ophthalmological findings included mucopurulent discharge from both the eyes and conjunctival chemosis. Left external auditory canal showed erythema and purulent discharge. Oral and genital mucosa was normal. Bilateral inguinal lymph nodes were palpable (left inguinal region: 4 nodes sized $2 \times 1 \mathrm{~cm}$ each. Right side: 1 node sized $2 \times 2 \mathrm{~cm}$ ). Lymph nodes were freely mobile and non-tender.

Blood investigations revealed $\mathrm{Hb} 12.1 \mathrm{~g} \%$, leukocytosis with a total leukocyte count of 14000 cells $/ \mathrm{mm}^{3}$, neutrophils 55\%, lymphocytes 35\%, Eosinophils $8 \%$, monocytes $2 \%$, ESR $12 \mathrm{~mm} /$ hour. Liver function test was deranged. Total bilirubin $1.0 \mathrm{mg} / \mathrm{dl}$, direct bilirubin $0.5 \mathrm{mg} / \mathrm{dl}$, total protein $6 \mathrm{~g} / \mathrm{dl}$, globulin $2.5 \mathrm{~g} / \mathrm{dl}$, SGOT 84 U/l, SGPT $132 \mathrm{U} / \mathrm{l}$, alkaline phosphatase 340. Skin biopsy taken from lesions over forearm revealed the following: Epidermis showed acanthosis, marked spongiosis, focal intra corneal pustule and sub epidermal 
bulla formation. Degeneration of basal layer with mild pigmentary incontinence was noted. Superficial dermis showed dense inflammatory cell infiltrate predominantly eosinophils and lymphocytes. Extravasated RBCs were also found (Figure 3 ).

Phenytoin was immediately withdrawn and substituted with tablet levetiracetam. The patient was treated with tablet prednisolone $60 \mathrm{mg}$ (gradually tapered), tab amoxicillin+clavulinic acid $625 \mathrm{mg}$, tab hydroxyzine 25 $\mathrm{mg}$, hydrocortisone ear drops, lubricating eye ointment and saline soaks for the oozing skin lesions. Within 2 days the patient improved symptomatically. Facial oedema, erythema and oozing of lesions also decreased (Figure 4). Patient was strictly advised to avoid phenytoin in future and discharged from the hospital.

\section{DISCUSSION}

Drug rash with eosinophilia and systemic symptoms (DRESS) syndrome, initially described as drug-induced hypersensitivity syndrome (DIHS), was first reported in 1936 during treatment with anticonvulsant drugs. ${ }^{2}$ Later on, the association with other drugs was established and the name 'DRESS syndrome' was suggested to describe this entity. It is an under-recognized and potentially lifethreatening hypersensitivity reaction associated with a variety of medications. $^{3}$
Aromatic anticonvulsants (phenytoin, phenobarbital, carbamazepine) and sulfonamides are the most common causes of DRESS syndrome but a number of other drugs including lamotrigine, allopurinol, non-steroidal antiinflammatory drugs, captopril, calcium channel blockers, mexiletine, fluoxetine, dapsone, terbinafine, metronidazole, minocycline and antiretroviral drugs have also been implicated. ${ }^{4}$ Clinical manifestations start within 1-8 weeks after drug intake with an incidence ranging from $1 / 1000$ to $1 / 10000$ exposures. ${ }^{5}$

The rash manifests as a diffuse erythematous eruption (morbiliform rash) on the face, upper trunk, and upper extremities, usually accompanied by fever, facial and periorbital edema. Lesions may later become vesicular or exfoliated. Desquamation may occur with healing. It has a mortality rate of about $10 \%$ due to visceral organ compromise especially liver failure. Infectious complications have also been described especially in patients treated with corticosteroids. ${ }^{6}$ Haematological abnormalities; especially eosinophilia and infectious mononucleosis-like atypical lymphocytosis are also common. Diagnostic criteria for DRESS is presented in (Table 1).

\section{Table 1: Diagnostic criteria for DRESS. ${ }^{7}$}

\begin{tabular}{|c|c|}
\hline RegiSCAR criteria for diagnosis of DRESS & Japanese groups criteria for diagnosis of DRESS/DIHS \\
\hline Hospitalisation & $\begin{array}{l}\text { Maculopapular rash developing }>3 \text { weeks after starting the } \\
\text { suspected drug }\end{array}$ \\
\hline Reaction suspected to be drug-related & $\begin{array}{l}\text { Prolonged clinical symptoms } 2 \text { weeks after discontinuation of the } \\
\text { suspected drug }\end{array}$ \\
\hline Fever $>38^{\circ} \mathrm{C}^{*}$ & Fever $>38^{\circ} \mathrm{C}$ \\
\hline Enlarged lymph nodes at a minimum of 2 sites $^{*}$ & Liver abnormalities (alanine aminotransferase >100U/L) \\
\hline Involvement of atleast 1 internal organ ${ }^{*}$ & Leucocyte abnormalities \\
\hline Blood count abnormalities ${ }^{*}$ & - $\quad$ Leucocytosis (>11 x 109/L) \\
\hline - Lymphocytes above or below normal limits & - $\quad$ Atypical lymphocytosis $(>5 \%)$ \\
\hline - Eosinophils above the laboratory limits & - $\quad$ Eosinophilia (>1.5 x $109 / \mathrm{L})$ \\
\hline \multirow[t]{2}{*}{ - Platelets below the laboratory limits } & Lymphadenopathy \\
\hline & Human Herpes-6 reactivation \\
\hline $\begin{array}{l}\text { Three out of four asteriksed }(*) \text { criteria are required for making } \\
\text { the diagnosis }\end{array}$ & $\begin{array}{l}\text { Diagnosis is confirmed by the presence of the } 7 \text { criteria (typical } \\
\text { DIHS) }\end{array}$ \\
\hline
\end{tabular}

\section{CONCLUSION}

Our patient showed typical manifestations of DRESS including fever, lymphocytosis, eosinophilia, liver involvement, and temporal association with drug intake. Hence the diagnosis of DRESS was made. The patient was promptly treated with systemic corticosteroids, topical and systemic antibiotics, and moisturisers, antihistaminic. The patient showed dramatic improvement and he was discharged with a strict advice to avoid phenytoin in future.

\section{Funding: No funding sources \\ Conflict of interest: None declared \\ Ethical approval: Not required}




\section{REFERENCES}

1. Camous X, Calbo S, Picard D, Musette P. Drug Reaction with eosinophilia and systemic symptoms: an update on pathogenesis. Curr Opin Immunol. 2012;24(6):730-5.

2. Saltzstein SL, Ackerman LV. Lymphadenopathy induced by anticonvulsant drugs and mimicking clinically pathologically malignant lymphomas. Cancer. 1959;12:164-82.

3. Hall DJ, Fromm JS. Drug reaction with eosinophilia and systemic symptoms syndrome in a patient taking phenytoin and levetiracetam: a case report. J Med Case Rep. 2013;7:2.
4. Tas S, Simonart T. Management of drug rash with eosinophilia and systemic symptoms (DRESS Syndrome): An Update. Dermatology. 2003;206:353-6.

5. Kumara R, Timshina DK, Thapa DM. Drug hypersensitivity syndrome. Indian $\mathrm{J}$ Dermatol Venereol Leprol. 2011;77:7-15.

6. Agu CC, Basheer H. DRESS syndrome associated with allopurinol. International Journal of Case Reports and Images. 2014;5(2):145-9.

7. Choudhary S, McLeod M, Torchia D, Romanelli P. Drug reaction with eosinophilia and systemic symptoms (DRESS) syndrome. J Clin Aesthet Dermatol. 2013;6(6):31-7.

Cite this article as: Devaraj Y, Belagola SD, Mukunda RS, Manchukonda R, Basavanaik P, Hasanabba AK, et al. Phenytoin induced drug rash with eosinophilia and systemic symptoms syndrome: a case report. Int J Basic Clin Pharmacol 2016;5:1148-51. 